\title{
Discussion on the Cultivation of Comprehensive Quality in the Teaching of Liberal Arts Physics
}

\author{
Chunqing $\mathrm{Xu}^{1, *}$ \\ ${ }^{1}$ School of physics University of electronic and science technology of China, Chengdu, China \\ *Corresponding author Email: $519634262 @ q q . c o m$
}

\begin{abstract}
The development of society needs comprehensive talents. Physics is the subject that has the greatest impact on the development of human society, is the epitome of the whole scientific development, and is one of the best subjects to cultivate the comprehensive quality of liberal arts students. Therefore, it is necessary for liberal arts students to learn physics. Discusses how to teach physics course of liberal arts under the goal of cultivating comprehensive quality. Discusses four emphases that should be emphasized in Liberal Arts Physics and the problems that should be paid attention to in the teaching process, and puts forward some suggestions.
\end{abstract}

Keywords: Physics, Liberal arts, Emphasis, Comprehensive quality.

\section{INTRODUCTION}

The successful people in society are often not ignorant. For example, Ma Yun and Hua Chunying are both foreign language majors. If they only know foreign languages, they can't achieve what they are today. Liberal arts students, represented by foreign language majors, can not only understand their own professional knowledge, but also need to constantly expand their knowledge, which will not only give them more development space, but also meet the needs of a large number of compound talents in national construction. Physics is the subject that has the greatest impact on the development of human society and the epitome of the whole scientific development. Learning physics can greatly expand the knowledge of liberal arts students, and physics is one of the best subjects to cultivate the comprehensive quality of liberal arts students. Since the 1990s, the research on Liberal Arts Physics has gradually deepened, and a comprehensive study has been made on the teaching content[1], teaching methods[2], teaching concept[3], and teacher team construction[4]. However, how to make the teaching of Liberal Arts Physics better serve the goal of cultivating comprehensive quality is not fully studied. On the basis of many years' teaching practice, this paper puts forward four emphases to serve the goal of cultivating the comprehensive quality. They are focusing on teaching the ideas and methods of physics, integrating theory with practice, integrating theory with frontier science and technology, and extending to other disciplines from the connection between physics and other disciplines. At the same time, this paper also analyzes the problems that should be paid attention to in Liberal Arts Physics teaching, and puts forward some suggestions on how to teach well.

\section{TEACHING THE BASIC IDEAS AND METHODS OF PHYSICS}

How does physics look at the world? This involves the basic ideas of physics, which are very meaningful for liberal arts students to establish a correct outlook on science and world. The method of physics research problems can be used for reference for liberal arts students. The ideas of physics involves many aspects, and the most basic content is the idea about the origin and test of theory. Physics is a logical and systematic science composed of laws (or principles) and theorems[5]. The laws in physics are summed up from practice, while the theorems are derived from laws through strict logic deduction, so the ultimate source of physics is practice. Almost everyone has been curious about the world since childhood, and they like to ask why. But the way physics looks at the world may surprise some people, because there is no reason for basic law or principle in physics. For example, why is the acceleration of an object proportional to the external force and inversely proportional to the mass of the object? It is a common mistake that many people often make to ask such questions. This is a typical example of misunderstanding of the source of theory. Laws or 
principles are summed up from practice, not derived, so there is no "why". Theory comes from practice, and its correctness must be constantly tested by practice, which is the only standard to test theory. These ideas are the basic foothold for studying the objective world and can not be violated. But in reality, there are many examples of violating these ideas. For example, Tan Shusheng, a Chinese scholar, founded the Standard Space-Time Theory[6]. He said that the theory can explain all previous experimental results and foresee some unexpected facts. However, there is no upper bound of the velocity of matter in any inertial system in this theory, and it is taken as a basic hypothesis of this theory. As the phenomenon of matter moving faster than light speed has not been recognized by the academic circles, this basic hypothesis has no practical basis. The theory comes from practice, and the theory without practical basis cannot be tenable.

There are many physical methods, such as the ideal model, the special situation method, the analysis and synthesis method, and the reverse thinking method, and so on. This paper takes the special situation method as an example to analyze how to combine the specific content to describe these research methods, and how to inspire students to improve their ability of studying problems. If a problem is too complex, it is difficult to distinguish the main factor from the secondary factor. In this case, the special situation method provides us with an entry point to study the problem. By studying a special situation which is easy to solve, we can get some valuable conclusions. Such method is called the special situation method, and is widely used in physics. The concept of quasi-static process in thermodynamics is a very typical example. The thermodynamic process is relatively complex, because the intermediate state is non-equilibrium state. However, in the quasi-static process, any intermediate state experienced by the system is an equilibrium state, which brings great convenience for us to study the problem. The Kano theorem which point out how to improve the efficiency of heat engine is based on the concept of quasi-static process. In the process of teaching, the author often inspires the students of liberal arts by means of induction. For example, in the future, when encountering problems that are difficult to deal with, we can not easily give up. Can we find out a special situation that is easier to solve through analysis like others? and draw some meaningful research conclusions by studying this special situation?

\section{INTEGRATING THEORY WITH PRACTICE TO ENRICH STUDENTS' COMMON SENSE OF LIFE}

On March 8, 2014, Malaysia Airlines MH370 lost contact. In a follow-up press conference, International Maritime Satellite Organization said that they analyzed the communication signals sent by MH370 and believed that the aircraft had fallen into the South Indian Ocean based on the Doppler effect. If the translator of the press conference has never heard of the Doppler effect, it will be difficult to complete the translation task accurately at that time. This example shows that people can't lack common sense. The theory of physics is closely connected with real life. Learning physics can make liberal arts students master a lot of common sense of life. For example, each of us can't live without light. How does light come out? Do buildings, trees, tables and other objects around us glow? Why do they glow? What light do they emit at room temperature? Why can't time go back according to the second law of thermodynamics? Why is the erosion on the right bank of the river in the northern hemisphere serious? And so on life common sense this article does not enumerate one by one. The common sense gained by learning physics is very beneficial to the expansion of liberal arts students' knowledge. In the teaching of Liberal Arts Physics, teachers should also pay attention to this, constantly enrich students' common sense of life, and meet the needs of comprehensive quality training.

\section{LINKING THEORY WITH FRONTIER SCIENCE AND TECHNOLOGY}

Science and technology are the primary productive forces. The application of steam engine, internal combustion engine, electric power, computer and other science and technology set off a wave of industrial revolution again and again, which has a profound impact on human life. Nowadays, many cutting-edge technologies, such as artificial intelligence, quantum technology, artificial sun, super capacitor, electromagnetic gun, etc., will have a profound impact on all aspects of human life in the future. The introduction of this aspect in Liberal Arts Physics is very helpful to expand the knowledge of liberal arts students and increase their understanding of the future social development trend. It is a content that must be paid attention to in the Liberal Arts Physics course aiming at the cultivation of comprehensive quality. For example, when we talk about flat-panel capacitors in electromagnetics, we can introduce the introduction of super capacitors. The super capacitors is made of activated carbon material, and the electrolyte solution is filled between the carbon porous electrodes. Because the activated carbon material has an ultra-high specific surface area of $1200 \mathrm{~m} 2 / \mathrm{g}$, the interface distance between the porous electrode is less than $1 \mathrm{~nm}$, which greatly increases the area and reduces the spacing, thus increasing the power storage ability. The super capacitors have a number of advantages. Its charging speed is fast; discharge cycle use times can reach 500000 times; high energy conversion efficiency; the composition of raw materials, production, storage and disassembly process are pollution-free. Once this 
technology enters the mature industrial production, the new super capacitor power system will replace all the electrochemical batteries from electric vehicles to notebook computers, which will have a profound impact on all aspects of people's lives.

\section{EXTENDS TO OTHER DISCIPLINES FROM THE CONNECTION BETWEEN PHYSICS AND OTHER DISCIPLINES}

The teaching content should be extended to other disciplines from the connection between physics and other disciplines, which helps to expand students' vision and knowledge, and is beneficial to the cultivation of comprehensive quality. There are many connections between physics and other disciplines. For example, research methods and theoretical structures. As mentioned above, the special situation method is used in physics. Economic problems are also very complex, and the influencing factors involve all aspects. Sometimes it is difficult to find out which are the main factors. For these problems, the special situation method is often used, for example, to study the price of securities. There are too many factors that affect the price of securities. Some accidental factors can make the price of a stock fluctuate greatly. In this case, the concept of efficient market is put forward, which is a typical example of applying the special situation method. Efficient market assumes that the whole market is fully competitive and all market participants accept information at the same time. Obviously, efficient market is a special situation of actual market. On the basis of efficient market, a series of theories and research results have been obtained, such as capital asset pricing model (CAPM) which is widely used in asset valuation, capital cost budget. In physics, different disciplines usually have a common theoretical structure. For example, it can be divided into two parts: kinematics and dynamics. We can use this structure model to extend to economics and even seismology. In physics, the trajectory of a rocket in the future can be accurately calculated. Why can't a country's GDP in the next few years be accurately calculated, and why the earthquake that may occur in a place in the future can't be accurately predicted. The fundamental reason lies in the fact that the dynamics part of economics and seismology is very imperfect. From the discussion of these problems, we can extend physics to other disciplines in the teaching of Liberal Arts Physics, so as to expand students' knowledge and meet the needs of comprehensive quality training.

\section{PROBLEMS NEEDING ATTENTION AND SUGGESTIONS}

In order to make Liberal Arts Physics play the role of cultivating students' comprehensive quality, teachers need to invest a lot of time in teaching. There is no ready-made textbook to refer to how to excavate the idea and method behind knowledge and how to expand the teaching content from physics to other disciplines. Only by the teachers' hard study, thinking and mutual communication. Some liberal arts students will inevitably feel that it is the most important to learn professional courses well, others are not so important, so they do not pay attention to Liberal Arts Physics. For this problem, teachers need to fully emphasize the importance of comprehensive quality training in class, and strive to better meet the requirements of comprehensive quality training, and pay attention to the four emphases mentioned above. In addition, it is necessary to make the teaching more vivid, humorous and interesting. Since liberal arts students don't take physics as their profession, it is suggested that the open book examination should be adopted. Because liberal arts students are weak in physics and mathematics, teachers should not teach a lot of physical formulas in the process of teaching. On the other hand, if we completely abandon the physical formula, the Liberal Arts Physics course will become a popular science lecture, which is not appropriate, because it is difficult to reveal the ideas and methods of physics and it is also difficult to integrate theory with practice well. Therefore, for the specific content of Liberal Arts Physics, how much physics formula should be taught and how deep it should be, teachers should give different treatment according to the classroom teaching effect.

\section{CONCLUSION}

Physics ideas are very meaningful for liberal arts students to establish a correct scientific view and material view. Physics research methods can be used for reference for liberal arts students to study problems. Rich common sense of life is necessary for any work. Integrating theory with cutting-edge science and technology is very helpful for liberal arts students to expand their knowledge and increase their understanding of the future social development trend. Extending the teaching content from physics to other subjects is helpful to expand students' horizons and knowledge. In the teaching of Liberal Arts Physics, the teaching of these contents plays an important role in the cultivation of students' comprehensive quality. In order to make liberal arts physics play a real role in cultivating students' comprehensive quality, teachers need to invest a lot of time and energy in teaching. Physics ideas and methods are contained in knowledge. In the process of learning, it is difficult for most students to dig them out, and then understand them. This requires teachers to integrate these valuable physics ideas and methods into classroom teaching by means of mining and induction, and inspire students to digest and absorb these ideas and methods by the means of induction. In addition, teachers also need to pay attention to the teaching methods, examination forms 
and the teaching of mathematical formulas.

\section{REFERENCES}

[1] Liu, L. M., Li, C. J., "Exploration of College Liberal Arts Physics Teaching". Physics and engineering, vol.14, no.1, pp. 59-60, 2004.

[2] Wang, Y., Lu, D. Q., "Practice and exploration of Liberal Arts Physics". Laboratory research and exploration, vol.28, no.12, pp.142-144, 2009.

[3] Ouyang, F. P., "Thinking and exploration of Liberal Arts Physics Teaching in Central South University", Higher education research of science and technology, vol.24, no.2, pp.51-54, 2005.
[4] Zhao, W., Chen. Y. H., "Practice and exploration of Liberal Arts Physics Education", China Electric Power Education, no.7, pp. 6-7, 2011.

[5] Xu, C, Q., "Grasping Basic Physical Theory Ideas, Improving Research and Innovation Capabilities", Applied Social Science, no.5, pp.306-310, 2014.

[6] Tan. S. S., "The Standard Space-Time Theory (1)", Journal of National University of Defense Technology, vol.1, pp.152-179, 1984. 